Die

\title{
Geschichte des Ursprungs
}

der

\section{belgischen Beghinen}

nebst

einer authentischen Berichtigung der im 17. Jahrhundert durch Verfälschung von Urkunden in derselben angestifteten Verwirrung.

Von

Dr. W. Wallmann.

Mit Abbildungen auf drei Tafeln.

Berlin, 1843.

Gedruckt und verlegt bei G. Reimer. 



\section{Seiner Excellenz}

dem

Wirklichen Geheimen Staats- und dirigirenden Minister der

Geistlichen, Unterrichts- und Medicinal-Angelegenheiten

\section{Herrn Dr. F. Eichhorn}

ehrerbietigst gewidmet. 
